\title{
The autooxidation process in linoleic acid screened by Raman spectroscopy
}

\author{
N. F. L. Machado, ${ }^{a}$ L. A. E. Batista de Carvalho, ${ }^{a}$ J. C. Otero ${ }^{b}$ \\ and M. P. M. Marques ${ }^{\mathrm{a}, \mathrm{c} *}$
}

\begin{abstract}
The chemical changes associated to the autooxidation process of linoleic acid (LA) were detected by Raman spectroscopy and interpreted in the light of density functional theory (DFT) calculations performed for both the fatty acid and its main oxidation products. The present methodology, applied for a six-day period upon induction of oxidation (through heating), allowed to understand the chemical modifications occurring during the oxidation process. Raman spectroscopy was shown to be a suitable and reliable technique for assessing the oxidation degree of fatty acid samples, particularly pure fatty acids, mainly when computational methods are used alongside to predict the spectral features of the distinct chemical entities involved. Screening of the oxidation process was mostly based on the loss of intensity of the bands assigned to LA cis-double bonds. Copyright $\odot 2012$ John Wiley \& Sons, Ltd.
\end{abstract}

Supporting information may be found in the online version of this article.

Keywords: linoleic acid; oxidation; assay for antioxidant activity; Raman spectroscopy; DFT calculations

\section{Introduction}

The oxidative deterioration of lipids has always been an issue regarding food quality, causing a nutritional value $\operatorname{loss}^{[1]}$ and leading to the appearance of undesirable odours and flavours in lipid containing foods - rancidity. Thus, several analytical methods have been developed aiming at an accurate assessment of the state of preservation of edible oils and other lipid-containing food products. $^{[2-4]}$ The majority of these methods are based on chromatographic or spectrophotometric techniques, which require a pre-treatment of the samples - these may introduce errors due to mishandling, or to the presence of contaminants and additives that may interfere with the results. ${ }^{[2,5]}$ Furthermore, the sample preparation is sometimes complex and often involves handling of hazardous chemicals. In fact, to this date, there is no simple and reliable method able to perform a direct measurement of the chemical content of edible oils, determining the presence of oxidation products. ${ }^{[5]}$

In order to fill this gap, in particular regarding the screening of fatty acids, attention has been paid to vibrational spectroscopy in the few last years. ${ }^{[5-9]}$ The assessment of either a fatty acid or a mixture (e.g. edible oils) through vibrational spectroscopy methods allows to gather information on the sample composition, as well as on the unsaturation pattern of the compounds present ${ }^{[8]}$ and on the corresponding molecular conformation (e.g. cis or trans). ${ }^{[10,11]}$ Furthermore, the presence of oxidation products is easily detected through analysis of the spectral pattern, which may be used to measure the degree of oxidation in either a fatty acid or a blended oil, ${ }^{[6,8,12]}$ by interpretation of the change in relative intensity of specific fatty acid bands.

Vibrational spectroscopy studies on fatty acids and their oxidation products have been carried out mainly by infrared (IR). Actually, the technical advances in this methodology, such as the introduction of Fourier transform IR (FTIR) and the development of improved detectors and sources, have greatly increased the sensitivity of the technique as well as its readiness, making it suitable for the detection of low concentrations of oxidation products in oils. A great deal of work has been developed in the last 15 years regarding the evaluation of the chemical composition of edible oils, ${ }^{[7,9]}$ aiming at the determination of the oil's geographic origin (e.g. for virgin oils) and at an accurate food quality control. ${ }^{[9]}$ In fact, the amount of work available within this field with recourse to IR has already lead IUPAC to establish standard procedures, based on thoroughly characterised bands (such as the one at $967 \mathrm{~cm}^{-1}$, assigned to non-conjugated trans-double bonds). ${ }^{[3]}$ Furthermore, FTIR has been applied to the determination of standard indices used in the classification of edible oils, such as the free fatty acids' content $^{[10]}$ or the iodine value and the saponification number. ${ }^{[13]}$ Regarding the oxidation status assessment, IR has not received special attention until recently, ${ }^{[4,14]}$ although encouraging results have been reported within this area in the last few years. ${ }^{[6,9,15]}$

Raman spectroscopy, in turn, has been increasingly recognised as a promising technique for screening the oxidation process in lipids. Although already applied for the characterisation, ${ }^{[16]}$ authentication, ${ }^{[17]}$ unsaturation profile assessment ${ }^{[18]}$ and free fatty acid content evaluation, ${ }^{[19]}$ it has not yet been fully explored as an accurate analysis method of oils and fats. Some work has recently been published dealing with fatty acid oxidation, clearly evidencing the suitability of the technique for this specific

* Correspondence to: M. P. M. Marques, Department of Life Sciences, Faculty of Science and Technology, University of Coimbra, Ap. 3046, 3001-401 Coimbra, Portugal.E-mail:pmc@ci.uc.pt

a Research Unit 'Molecular Physical Chemistry', University of Coimbra, Portugal

b Department of Physical-Chemistry, Faculty of Sciences, University of Málaga, Spain

c Department of Life Sciences, Faculty of Science and Technology, University of Coimbra, Portugal 
task. ${ }^{[5,7,8,11,12]}$ Actually, Raman spectroscopy presents several advantages as compared to FTIR, namely its non-invasiveness, high sensitivity and good reproducibility, apart from the fact that it needs virtually no sample preparation, enabling rapid and nondestructive measurements and yielding unique fingerprint spectra for each compound (in a mixture). In fact, the preparation procedure required for IR spectra collection (using solvents such as solid $\mathrm{KBr}$ ) may interfere with the concentration of the compound(s) to analyse and lead to reproducibility problems. This difficulty may be overcome by attenuated total reflectanceFTIR, which (as Raman) does not need any sample preparation, but requires an elaborate cleaning procedure of the crystal in order to avoid the so-called 'memory effect'. ${ }^{[5]}$ Furthermore, the presently available portable Raman devices, enable, in a near future, in situ analysis of a sample, that will be of undisputable relevance for application in food industry. ${ }^{[7]}$

In order to assess the potential antioxidant capacity of new compounds - acting as free radical scavengers - several standard methods for evaluation of antioxidant activity have been developed, either based on hydrogen atom transfer (HAT) reactions (1), or on electron transfer (ET) processes (2). In the former (HAT), a competition reaction scheme is generally followed, during which the antioxidant and the substrate will compete for the scavenging of thermally generated peroxyl radicals - oxygen radical absorbance capacity, and total radical trapping antioxidant parameter tests being the most widely used. ${ }^{[20,21]}$ The ET methods, in turn, are colorimetric assays based on the reduction of a standard oxidant (added to the analysed sample) that changes colour in the process. Thus, they rely on the measurement of the sample's absorbance at distinct wavelengths - the absorption maxima of the standard oxidant or radical and of its corresponding reduced species. The absorbance change upon reduction, directly related to concentration, yields the degree of sample reduction and consequently the activity of the tested antioxidant. These kind of experiments encompass the total phenol assay by Folin-Ciocalteau, the Trolox equivalence antioxidant capacity test (also known as ABTS, from 2,2'-azino-bis(3-ethylbenzothiazoline-6-sulfonic acid) which is the reduced species), the ferric ion reducing antioxidant power method and the cupric ion reducing antioxidant capacity assay. ${ }^{[20-22]}$

Since linoleic acid (LA) is a fatty acid widely used as an oxidation target in many of these standard assays for antioxidant capacity, ${ }_{1}{ }^{20]}$ the screening of its oxidation status through Raman spectroscopy will hopefully lay the grounds for the development of a simple, reliable and accurate technique for the evaluation of the antioxidant activity of a wide range of compounds. With a view to assess the potential of Raman spectroscopy for the development of such a standard antioxidant assessment technique, it was applied to the autooxidation process of LA, followed for a six-day period upon induction of oxidation (through heating). Computational simulations, by quantum mechanical calculations at the density functional theory (DFT) level, have been undertaken for the systems under study - LA and its main oxidation products - with the purpose of assisting the assignment of the corresponding spectral features, and its changes throughout the experiment.

\section{Experimental}

\section{Chemicals}

LA (cis-9,cis-12-octadecadienoic acid) ( $\geq 99 \%$ ) was purchased from Sigma-Aldrich Química S.A. (Sintra, Portugal) and stored at $-20^{\circ} \mathrm{C}$ (to avoid oxidation).

\section{Raman spectroscopy}

The Raman spectra were obtained at room temperature, in a triple monochromator Jobin-Yvon T64000 Raman system (focal distance $0.640 \mathrm{~m}$, aperture $f / 7.5$ ) equipped with holographic gratings of 1800 grooves $\mathrm{mm}^{-1}$. The premonochromator stage was used in the subtractive mode. The detection system was a liquid nitrogen cooled non-intensified $1024 \times 256$ pixel (1") charge coupled device chip.

The $514.5 \mathrm{~nm}$ line of an $\mathrm{Ar}^{+}$laser (Coherent, model Innova 300-05) was used as the excitation radiation, providing ca. $80 \mathrm{~mW}$ at the sample position. $\mathrm{A} 90^{\circ}$ geometry between the incident radiation and the collecting system was employed. The entrance slit was set to $200 \mu \mathrm{m}$, as well as the slit between the premonochromator and the spectrograph. The samples were sealed in Kimax glass capillary tubes of $0.8 \mathrm{~mm}$ inner diameter. Under the above-mentioned conditions, the error in wavenumbers was estimated to be within $1 \mathrm{~cm}^{-1}$.

The spectra were always collected with an acquisition time of $10 \mathrm{~s}$ for an average of ten accumulations, except for the region between 3200 and $3600 \mathrm{~cm}^{-1}$ for which an integration time of $30 \mathrm{~s}$ was used.

\section{Quantum mechanical calculations}

The quantum mechanical calculations were performed using the GAUSSIAN 03W program, ${ }^{[23]}$ within the DFT approach in order to properly account for the electron correlation effects (particularly important in this kind of unsaturated systems). The widely employed hybrid method denoted by B3LYP, which includes a mixture of HF and DFT exchange terms and the gradientcorrected correlation functional of Lee, Yang and Parr ${ }^{[24]}$ as proposed and parameterised by Becke ${ }^{[25]}$ was used, along with the double-zeta split valence basis set $6-31 \mathrm{G}^{* *}$. $^{[26]}$

Molecular geometries were fully optimised by the Berny algorithm, using redundant internal coordinates: ${ }^{[27]}$ the bond lengths to within ca. $0.1 \mathrm{pm}$ and the bond angles to within ca. $0.1^{\circ}$. The final root-mean-square gradients were always less than $3 \times 10^{-4}$ hartree.bohr ${ }^{-1}$ or hartree.radian ${ }^{-1}$. No geometrical constraints were imposed on the molecules under study.

Calculation of the harmonic vibrational wavenumbers was carried out for all conformations (at the same level of theory) in order to check for minima in the potential energy surface and to obtain the predicted vibrational pattern (both Raman and IR) of the compounds. Wavenumbers above $400 \mathrm{~cm}^{-1}$ were scaled by a factor of $0.9614^{[28]}$ before comparing them with the experimental data, in order to correct for the anharmonicity of the normal modes of vibration.

\section{Oxidation experiments}

After obtaining the Raman spectrum of freshly unfrozen LA, about $1 \mathrm{~g}$ of fatty acid was placed in an air-circulating oven at a temperature of $c a .60^{\circ} \mathrm{C}$, inside a punctured eppendorf wrapped in aluminium foil (in order to avoid photo-induced oxidation). For a six-day period, samples were collected every day, and the corresponding Raman spectra were obtained.

\section{Results and discussion}

\section{General spectral assignment}

With a view to assist the interpretation of the Raman data gathered along the autooxidation process of LA, DFT calculations were performed yielding LA's minimum energy conformation (Fig. 1) as well as its predicted Raman spectrum. The same 
theoretical procedure was undertaken for the acid's major autooxidation products, two hydroperoxide species (Fig. 1). This combined spectroscopic (Raman) and theoretical approach constitutes a relevant tool for the accurate interpretation of the experimental vibrational data, allowing a full understanding of the chemical changes due to the oxidation process over time.

The Raman spectrum obtained for LA (Fig. 2) comprises the typical vibrational features of a cis-fatty acid, namely the band at $3013 \mathrm{~cm}^{-1}$ (assigned to the symmetric $\mathrm{v}(\mathrm{CH})$ mode associated to the double bonds) and the signal at $1659 \mathrm{~cm}^{-1}$, the most intense of the spectrum (ascribed to the in-phase $v(C=C)$ stretching, Table 1).

Some vibrational spectral bands have been used in previous studies in order to monitor lipid oxidation, namely at 1266 , ca. 1660 and ca. $3010 \mathrm{~cm}^{-1}$. ${ }^{[6,8]}$ The $\mathrm{CH}_{2}$ and $\mathrm{CH}_{3}$ symmetric and antisymmetric stretching modes (aliphatic moiety of the molecule) presently observed in the high wavenumber region ( 2850 to $3000 \mathrm{~cm}^{-1}$ ) are sensitive to the lateral packing effects of the hydrocarbon chains ${ }^{[29]}$ and can therefore be used as a measure of the oxidation degree of the sample. These comprise a shoulder at $2961 \mathrm{~cm}^{-1}$, assigned to $\mathrm{v}\left(\mathrm{CH}_{3}\right)_{\text {as }}$, and two broad bands at 2931 and $2904 \mathrm{~cm}^{-1}$, corresponding to the symmetric and antisymmetric $(\mathrm{CH})$ stretchings of the aliphatic chains (Table1). Two features due to antisymmetric stretching modes of $\mathrm{CH}_{2}$ aliphatic groups appear at 2875 and $2855 \mathrm{~cm}^{-1}$, the former not being affected by oxidation which allows its use for spectral normalisation in this region, enabling to detect oxidation-induced intensity in the remaining bands. The feature at $2855 \mathrm{~cm}^{-1}$ arises mainly from the antisymmetric stretching of the methylene group between the two chain double bonds, which is annihilated by oxidation (Fig. 1).

The $1500-1800 \mathrm{~cm}^{-1}$ spectral range also contains signals which are prone to be affected by the oxidation process (Fig. 2). The interval between 1600 and $1750 \mathrm{~cm}^{-1}$ is particularly important, since it reflects variations due to conformational changes (namely cis-trans) and to the occurrence of conjugated unsaturated systems (e.g. in hydroperoxides, Fig. 1) that arise upon oxidation of the fatty acid. Additionally, the generation of secondary oxidation products, such as conjugated aldehydes, dienes and trienes (Fig. S1, Supplementary Material) may also be monitored by the occurrence of distinct spectral features within this interval. ${ }^{[8,15]}$ The sample of pure LA displays a very weak signal at $1744 \mathrm{~cm}^{-1}$ corresponding to the carboxylic $v_{\mathrm{C}=\mathrm{O}}$, a strong band at $1659 \mathrm{~cm}^{-1}$ (the most intense one in the spectrum), and a shoulder at $1640 \mathrm{~cm}^{-1}$ ascribed to the out-ofphase stretching of the cis- $\mathrm{C}=\mathrm{C}$ bonds (Table 1).

The LA band at $1441 \mathrm{~cm}^{-1}$, ascribed to the $\mathrm{CH}_{2}$ scissoring (aliphatic chains), is remarkably unchanged during the oxidation experiment, thus being suitable for the normalisation of the spectra collected after oxidation, at distinct time-points. In fact,

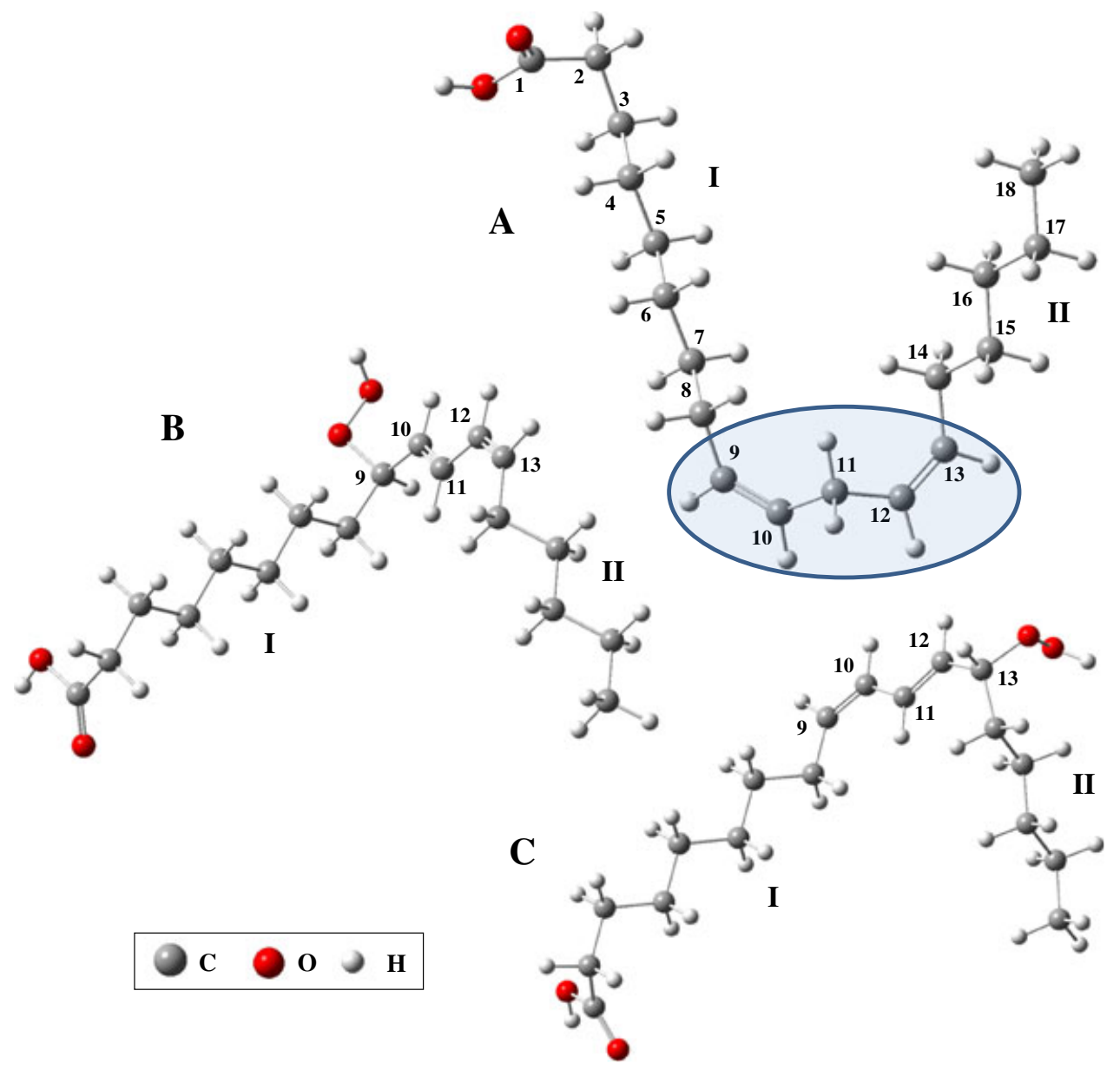

Figure 1. Calculated (B3LYP/6-31G**) lowest energy conformations for linoleic acid (A) and its two main autooxidation products (hydroperoxides) ( $B$ and $C)$. The highlighted area represents the major oxidation sites. I and II stand for the two different aliphatic moieties in these systems. This figure is available in colour online at wileyonlinelibrary.com/journal/jrs 

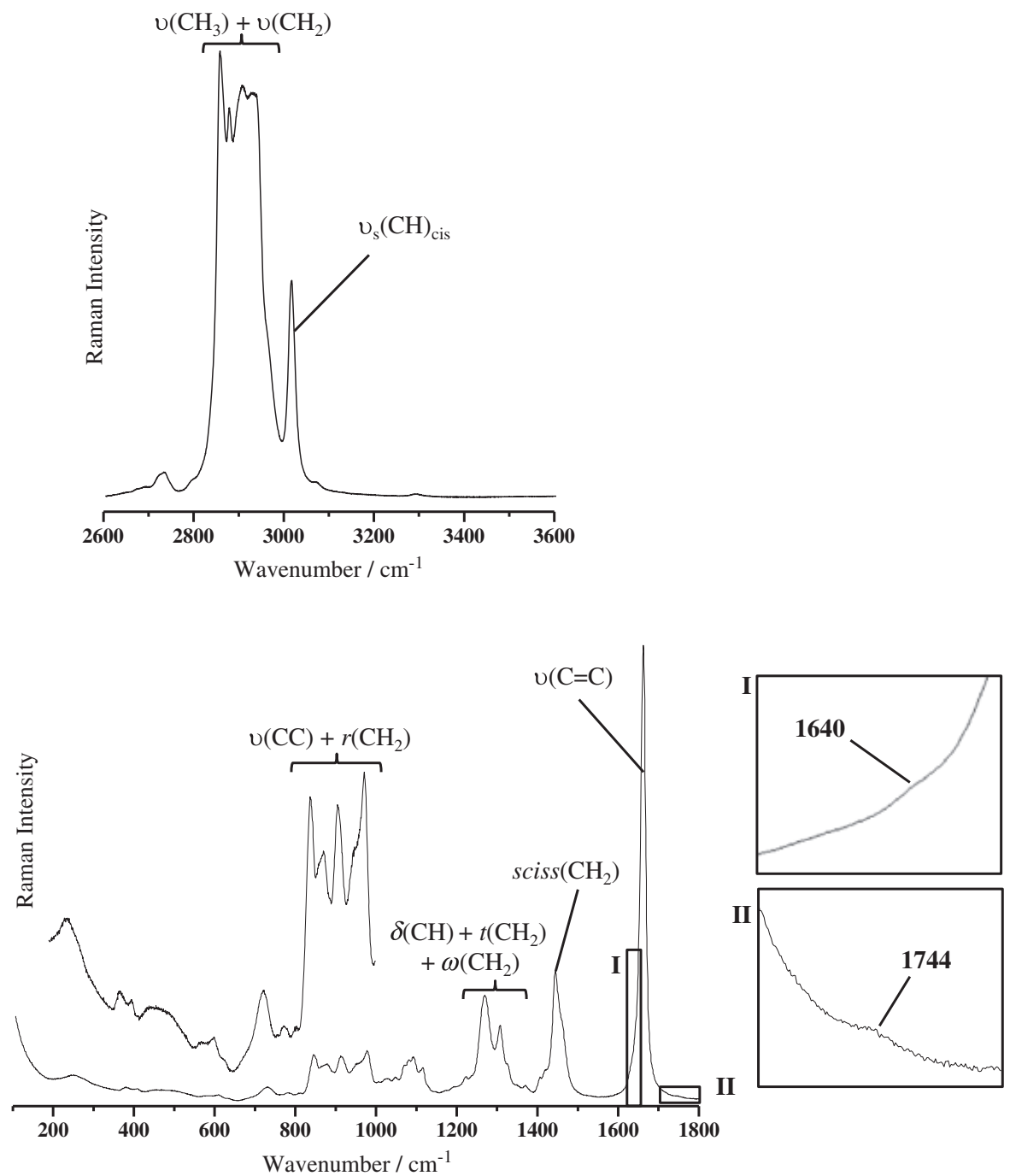

Figure 2. Experimental Raman spectrum $\left(100-1800 \mathrm{~cm}^{-1}\right.$ and $2600-3600 \mathrm{~cm}^{-1}$, at room temperature) for pure linoleic acid. (I and II correspond to spectral expansions).

the ratio between the intensity of this band and that of the signal at ca. $1660 \mathrm{~cm}^{-1}$, ascribed to the $\mathrm{v}(\mathrm{C}=\mathrm{C})$ modes, has been previously proposed as a measure of the oxidation degree of fatty acid samples. ${ }^{[18]}$ The signal at $1303 \mathrm{~cm}^{-1}$ corresponds to the $\mathrm{CH}_{2}$ twisting modes (aliphatic chains), with a minor contribution from the $\mathrm{OH}$ bending, and the one at $1266 \mathrm{~cm}^{-1}$ is assigned to the in-plane $\mathrm{CH}$ bending deformations from the cis-double bonds, coupled to the $\mathrm{CH}_{2}$ rocking modes from the molecule's moiety II (Fig. 1) from the methylene between the two double bonds (Table 1). Therefore, this band is expected to suffer major intensity changes upon oxidation. ${ }^{[8]}$

When analysing the spectral interval between 1200 and $800 \mathrm{~cm}^{-1}$, two intense features can be readily seen: an assembly of four superimposed bands between 1120 and $1060 \mathrm{~cm}^{-1}$ and another group between 980 and $840 \mathrm{~cm}^{-1}$ encompassing five bands, both sets displaying similar intensities (Fig. 2). The assignment of the first one is rather complex, as several vibrational modes contribute to the same signal, thus being virtually impossible to relate any change within this region with the oxidation process. In the $980-840 \mathrm{~cm}^{-1}$ interval, in turn, the bands are well defined and can be assigned to specific vibrational modes. The signal at $973 \mathrm{~cm}^{-1}$, ascribed to the out-of-phase deformation of the $\mathrm{CH}$ olefinic moiety, is quite suitable for monitoring the oxidation of the fatty acid, involving the formation of cis-trans conjugated systems. The band at 947 $\mathrm{cm}^{-1}$ is also related with to the oxidation site (Fig. 1), since it involves the rocking of the $\mathrm{CH}_{2}$ group located between the two double bonds in the LA molecule, coupled to the $v(C-C)$ vibration of the bonds connecting the olefinic carbons with the aliphatic ones, with a minor contribution from the in-plane $\mathrm{CH}$ deformation of the olefinic groups (Table 1). The $\left(\mathrm{C}^{10} \mathrm{C}^{11} \mathrm{C}^{12}\right)$ deformation of the LA's saturated moiety (Fig. 1) yields a feature at $910 \mathrm{~cm}^{-1}$, characteristic from this system and prone to undergo changes during the oxidation experiment. On the contrary, the remaining two bands detected in this region, at 873 and $841 \mathrm{~cm}^{-1}$ (Fig. 2), do not give any information on the oxidation process as they are associated to molecular groups far apart from the unsaturation sites (Table 1).

Below $800 \mathrm{~cm}^{-1}$, only low intensity broad bands are observed (Fig. 2), namely out-of-plane deformations of both the olefinic $\mathrm{CH}$ and $\mathrm{OH}$ groups, at 726 and $604 \mathrm{~cm}^{-1}$, respectively. At lower wavenumbers, the Raman signals are generally originated by vibrations involving the skeleton's heavy atoms: the feature at $403 \mathrm{~cm}^{-1}$ corresponds to the CCC deformation of the aliphatic 


\begin{tabular}{|c|c|c|c|c|c|}
\hline \multicolumn{2}{|c|}{$\begin{array}{l}\text { Experimental Raman Wavenumbers } \\
\left(\mathrm{cm}^{-1}\right)\end{array}$} & \multicolumn{3}{|c|}{${ }^{\mathrm{a} C a l c u l a t e d}$} & \multirow[t]{2}{*}{${ }^{\mathrm{b}}$ Assignment } \\
\hline LA & sample at day 6 & LA & HP 1 & $\mathrm{HP} 2$ & \\
\hline & $3370 / 3600$ & & 3622 & 3624 & $v(\mathrm{OH})_{\text {perox. }}$ \\
\hline $3415 / 3555$ & & 3608 & 3609 & 3608 & $\mathrm{v}(\mathrm{OH})_{\text {carbox. }}$ \\
\hline 3290 & 3292 & & & & $1640+1659$ \\
\hline 3068 & 3071 & & & & FR ((1416+ 1659);3013) \\
\hline 3013 & 3013 & 3029 & 3034 & 3035 & $v_{s}(\mathrm{CH})_{\text {cis }}$ \\
\hline 2961 & 2959 & 2951 & 2951 & 2946 & $v_{\text {as }}\left(\mathrm{CH}_{3}\right)_{\text {met. }}$ \\
\hline 2931 & 2928 & 2936 & 2936 & 2936 & $\mathrm{v}_{s}\left(\mathrm{CH}_{2}\right)_{\text {aliph. }}$ \\
\hline \multirow[t]{3}{*}{2904} & 2908 & 2920 & 2921 & 2920 & $v_{s}\left(\mathrm{CH}_{3}\right)+v_{a s}\left(\mathrm{CH}_{2}\right)_{\text {aliph. }}$ \\
\hline & & 2918 & 2920 & 2920 & \\
\hline & & 2918 & 2017 & 2918 & \\
\hline 2875 & 2875 & 2895 & 2895 & 2896 & $v_{\text {as }}\left(\mathrm{CH}_{2}\right)_{\text {aliph. }}$ \\
\hline 2855 & 2856 & 2877 & & & $v_{\text {as }}\left(C^{11} H_{2}\right)$ \\
\hline 2793 & 2790 & & & & combination mode \\
\hline 2722 & & & & & combination modes \\
\hline \multirow[t]{2}{*}{1744} & 1737 & 1776 & 1776 & 1776 & $v(C=O)_{\text {carbox }}$ \\
\hline & 1695 & & & & ${ }^{c} v(C=O)_{\text {aldehydes }}$ \\
\hline 1659 & 1659 & 1676 & & & $v(C=C)_{i p h}$ \\
\hline \multirow[t]{3}{*}{1640} & & 1670 & & & $v(C=C)_{\text {ooph. }}$ \\
\hline & 1635 & & 1661 & 1662 & $v(C=C)_{\text {iph. }}+{ }^{c} v(C=C)_{\text {conj. }}$ \\
\hline & 1597 & & 1622 & 1623 & $v(C=C)_{o o p h}$ \\
\hline 1456 & 1457 & 1457 & 1456 & 1456 & $r\left(\mathrm{CH}_{3}\right)$ \\
\hline 1441 & 1440 & 1442 & 1442 & 1440 & sciss. $\left(\mathrm{CH}_{2}\right)_{\text {aliph. }}$ \\
\hline \multirow[t]{2}{*}{1416} & 1418 & 1437 & 1437 & 1435 & sciss. $\left(\mathrm{CH}_{2}\right)_{1}$ \\
\hline & & 1425 & 1426 & 1426 & \\
\hline \multirow[t]{2}{*}{1402} & 1403 & 1388 & 1395 & 1397 & $\delta(\mathrm{CH})_{\text {olef. }}$ \\
\hline & & 1387 & & & \\
\hline 1365 & 1367 & 1374 & 1372 & 1374 & $\delta_{5}\left(\mathrm{CH}_{3}\right)$ \\
\hline \multirow[t]{2}{*}{1346} & 1346 & 1342 & 1333 & 1343 & $\omega\left(\mathrm{CH}_{2}\right)_{\text {aliph. }}+\delta(\mathrm{OH})_{\text {carbox. }}$ \\
\hline & & 1336 & & & \\
\hline \multirow[t]{2}{*}{1320} & 1322 & 1328 & 1323 & 1312 & $\omega\left(\mathrm{CH}_{2}\right)_{l}$ \\
\hline & & 1310 & 1312 & 1307 & \\
\hline \multirow[t]{2}{*}{1303} & 1303 & 1287 & 1285 & 1284 & $t\left(\mathrm{CH}_{2}\right)_{\text {aliph. }}$ \\
\hline & & 1279 & & & \\
\hline \multirow[t]{4}{*}{1266} & 1256 & 1258 & 1256 & 1261 & $\delta(\mathrm{CH})_{\text {cis }}+t\left(\mathrm{CH}_{2}\right)_{1}+\omega\left(\mathrm{CH}_{2}\right)_{11}+{ }^{\mathrm{d}} \omega\left(\mathrm{C}^{11} \mathrm{H}_{2}\right)+{ }^{\mathrm{e}} \delta(\mathrm{CH})_{\text {trans }}$ \\
\hline & & 1254 & 1250 & 1255 & \\
\hline & & 1248 & 1245 & 1246 & \\
\hline & & 1238 & & & \\
\hline 1223 & 1234 & 1213 & 1226 & 1227 & $\omega\left(\mathrm{CH}_{2}\right)_{\|}$ \\
\hline 1219 & 1221 & 1211 & 1212 & 1214 & $t\left(\mathrm{CH}_{2}\right)_{1}$ \\
\hline \multirow[t]{2}{*}{1190} & 1193 & 1203 & 1208 & 1212 & $t\left(\mathrm{CH}_{2}\right)_{1}+{ }^{\mathrm{f}} \delta(\mathrm{CH})_{\text {olef. }}+\delta(\mathrm{OH})_{\text {carbox. }}$ \\
\hline & & & 1207 & 1202 & \\
\hline \multirow[t]{2}{*}{1165} & 1164 & 1179 & 1186 & 1187 & $\delta(\mathrm{OH})_{\text {carbox. }}+\omega\left(\mathrm{CH}_{2}\right)_{1}+t\left(\mathrm{CH}_{2}\right)_{\| 1}+{ }^{\mathrm{e}} \mathrm{v}(\mathrm{C}-\mathrm{C})_{\text {conj. }}+{ }^{\mathrm{c}} \mathrm{v}(\mathrm{C}-\mathrm{C})$ \\
\hline & & 1174 & 1179 & 1179 & \\
\hline \multirow[t]{2}{*}{1142} & & 1157 & & & $\mathrm{v}(\mathrm{C}-\mathrm{O})_{\text {carbox. }}+\delta(\mathrm{OH})_{\text {carbox. }}+t\left(\mathrm{CH}_{2}\right)_{1}$ \\
\hline & ${ }^{g} 1123$ & & 1140 & 1139 & $v(C-C)_{\text {olef. }}+v(C-O)_{\text {perox. }}$ \\
\hline 1112 & 1111 & 1091 & 1122 & 1115 & $\delta(\mathrm{CH})_{\text {olef. }}+t\left(\mathrm{CH}_{2}\right)_{\text {aliph. }}+r\left(\mathrm{CH}_{3}\right)+{ }^{\mathrm{d}} t\left(\mathrm{C}^{11} \mathrm{H}_{2}\right)+{ }^{\mathrm{e}} \delta(\mathrm{CH})_{\text {perox. }}$ \\
\hline 1088 & 1082 & 1089 & 1088 & 1090 & $t\left(\mathrm{CH}_{2}\right)_{\| 1}+r\left(\mathrm{CH}_{3}\right)+{ }^{\mathrm{d}} t\left(\mathrm{C}^{11} \mathrm{H}_{2}\right)+{ }^{\mathrm{f}} \delta(\mathrm{CH})_{\text {olef. }}$ \\
\hline 1077 & 1077 & 1071 & 1070 & 1072 & $t\left(\mathrm{CH}_{2}\right)_{1}+v(\mathrm{C}-\mathrm{O})_{\text {carbox. }}+\delta(\mathrm{OH})_{\text {carbox. }}$ \\
\hline \multirow[t]{2}{*}{1066} & 1065 & 1055 & 1052 & 1061 & $v(\mathrm{C}-\mathrm{C})_{1}+v(\mathrm{C}-\mathrm{O})_{\text {carbox. }}+{ }^{e} \mathrm{v}(\mathrm{C}-\mathrm{O})_{\text {perox. }}+t\left(\mathrm{CH}_{2}\right)_{1}$ \\
\hline & & & 1051 & 1045 & \\
\hline \multirow[t]{2}{*}{1044} & 1041 & 1029 & 1028 & 1029 & $v(C-C)_{a l i p h}$. \\
\hline & & 1028 & 1025 & 1029 & \\
\hline 1021 & 1025 & 1023 & 1025 & 1024 & $v(C-C)_{1}$ \\
\hline \multirow[t]{2}{*}{1001} & & 1002 & & & $v(C-C)_{\text {aliph. }}+v(C-C)_{\text {olef. }}$ \\
\hline & & 995 & & & \\
\hline
\end{tabular}


Table 1. (Continued)

Experimental Raman Wavenumbers $\left(\mathrm{cm}^{-1}\right)$
${ }^{\mathrm{a}}$ Calculated

${ }^{\mathrm{b}}$ Assignment

\begin{tabular}{|c|c|c|c|c|c|}
\hline LA & sample at day 6 & LA & HP 1 & HP 2 & \\
\hline \multirow[t]{3}{*}{973} & 973 & 980 & 995 & 993 & $\gamma(\mathrm{CH}=\mathrm{CH})_{\text {ooph. }}+{ }^{\mathrm{d}} \mathrm{v}(\mathrm{C}-\mathrm{C})_{\text {olef. }}+\mathrm{v}(\mathrm{C}-\mathrm{C})_{\text {aliph. }}$ \\
\hline & & 978 & 976 & 985 & \\
\hline & & 974 & & & \\
\hline 947 & 952 & 933 & & & $r\left(\mathrm{C}^{11} \mathrm{H}_{2}\right)+\mathrm{v}\left(\mathrm{C}^{10}-\mathrm{C}^{11}\right)+\mathrm{v}\left(\mathrm{C}^{11}-\mathrm{C}^{12}\right)+\delta(\mathrm{CH})_{\text {olef. }}$ \\
\hline 910 & 907 & 894 & & & $\Delta\left(\mathrm{C}^{10} \mathrm{C}^{11} \mathrm{C}^{12}\right)$ \\
\hline \multirow[t]{2}{*}{873} & 872 & 867 & 859 & 847 & $r\left(\mathrm{CH}_{3}\right)+v(\mathrm{C}-\mathrm{C})_{\|}+r\left(\mathrm{CH}_{2}\right)_{1}$ \\
\hline & & 863 & & & \\
\hline 841 & 844 & 846 & 844 & 841 & $v(\mathrm{C}-\mathrm{C})_{1}+r\left(\mathrm{CH}_{2}\right)_{1}$ \\
\hline 805 & & 801 & 796 & 803 & $\mathrm{v}\left(\mathrm{C}^{1} \mathrm{C}^{2}\right)+r\left(\mathrm{CH}_{2}\right)_{1}$ \\
\hline 777 & 779 & 756 & 756 & & $\Delta(\mathrm{OCO})_{\text {carbox. }}+r\left(\mathrm{CH}_{2}\right)_{1}$ \\
\hline 726 & 722 & 726 & 744 & 766 & $\gamma(\mathrm{CH}=\mathrm{CH})_{\text {cis }}$ \\
\hline 680 & & 695 & & & $\gamma\left(C^{9} \mathrm{H}=\mathrm{C}^{10} \mathrm{H}\right)$ \\
\hline 604 & 601 & 597 & 596 & 598 & $\gamma(\mathrm{OH})_{\text {carbox. }}$ \\
\hline \multirow[t]{4}{*}{576} & 584 & & & & $\Delta\left(C^{8} C^{9}=C^{10}\right)+\Delta\left(C^{11} C^{12}=C^{13}\right)$ \\
\hline & ${ }^{9} 490$ & & 481 & 480 & $\Delta(\mathrm{C}-\mathrm{C}=\mathrm{C})_{\text {both }}+\Delta(\mathrm{CCO})_{\text {perox. }}+\gamma(\mathrm{OH})_{\text {carbox. }}$ \\
\hline & ${ }^{9} 456$ & & 466 & 474 & $\Delta(\mathrm{COO})_{\text {perox. }}+\Delta(\mathrm{CCC})_{\text {aliph. }}+\gamma(\mathrm{OH})_{\text {carbox. }}$ \\
\hline & & & 440 & 460 & \\
\hline 403 & 402 & 406 & 406 & 398 & $\Delta(C C C)_{\text {aliph. }}+\Gamma(C C=C)$ \\
\hline 373 & 372 & 368 & & & $\Delta(\mathrm{CCC})_{\|}$ \\
\hline \multirow[t]{2}{*}{241} & 217 & 248 & 235 & 234 & skeletal mode \\
\hline & & & 222 & & \\
\hline
\end{tabular}

chains coupled to $\mathrm{C}=\mathrm{C}-\mathrm{C}$ out-of-plane deformations of the olefinic groups. The band at $373 \mathrm{~cm}^{-1}$ is related to the CCC deformations of the aliphatic chain II and the signal at $241 \mathrm{~cm}^{-1}$ arises from a skeletal mode (Table 1). It should be reminded that oxidation leads, in a first stage, to the transformation of the cis-cis molecule into a cis-trans conjugated system (Fig. 1), therefore strongly altering the molecule skeleton's architecture which leads to changes in this region of the Raman spectrum.

\section{Influence of the oxidation process in the Raman pattern}

\section{$3600-2700 \mathrm{~cm}^{-1}$ spectral region}

The variations observed in this spectral range, upon oxidation, are mainly due to the formation of hydroperoxides and smallchain alcohols (Fig. S1), as well as to changes in the aliphatic chain architecture and corresponding saturation degree (detected below $3100 \mathrm{~cm}^{-1}$ ).

Although being often undetectable by Raman spectroscopy, the $v(\mathrm{OH})$ bands were observed upon a thorough scan of the 3600-3200 cm $\mathrm{cm}^{-1}$ spectral interval (Fig. S2, Supplementary Material). A very weak broad band between ca. 3555 and $3415 \mathrm{~cm}^{-1}$ is detected at day zero, being clearly more intense at the end of the experiment (six days after) (Table 1, Fig S2). This is due to the presence of an increasing number of $\mathrm{OH}$ groups in the sample, contributing to this feature, belonging either to the primary hydroperoxides or to secondary oxidation products
(Figs. 1 and S1). Even though this is a good indication of the oxidation process, several distinct chemical systems contribute to the increase in this band's intensity which renders it quantitatively meaningless.

Below $3100 \mathrm{~cm}^{-1}$, important changes can be observed in the Raman profile upon oxidation (Fig. S3, Supplementary Material): the intensity of the $v_{s}(C H)$ of cis-double bonds, at $3013 \mathrm{~cm}^{-1}$, decreases continuously (Fig. S3). This behaviour is to be expected, since the oxidation process leads to the disruption of the isolated cis-double bonds, and to the formation of a cis-trans conjugated system. On the other hand, the bands at 2931, 2904 and 2855 $\mathrm{cm}^{-1}$ (Fig. S3), also display well-defined intensity trends. The signal at $2875 \mathrm{~cm}^{-1}$, in turn, does not to vary significantly upon oxidation, thus being used to normalise this spectral region. The superimposed bands detected between 2900 and $2950 \mathrm{~cm}^{-1}$ increase upon oxidation (Fig. S3) thanks to the contribution of the symmetric and antisymmetric $\left(\mathrm{CH}_{2}\right)$ stretching modes from the lateral chains I and II (Fig. 1) of the newly formed peroxides (Table 1). Furthermore, the signal at $2855 \mathrm{~cm}^{-1}$ decreases during oxidation (Fig. S3), as it is related to the $\mathrm{CH}_{2}$ located between the two double bonds, specific from non-oxidised LA (Table 1, Fig. 1).

Additionally, aiming at an accurate assessment of the bands due to the oxidation process and of their intensity variation tendency, the spectrum of pure LA (at day 0 ) was subtracted from each spectrum collected during the experiment (one per day, for 6 days). Discarding the negative profiles resulting from the decrease in some LA bands (Fig. 3), four new visible signals 
deserve attention: (1) at $2983 \mathrm{~cm}^{-1}$, assigned to the $\mathrm{v}(\mathrm{CH})$ of the cis-double bond from the pure fatty acid (in agreement with the calculations); (2) at 2944, 2926 and $2907 \mathrm{~cm}^{-1}$ (Fig. 3) ascribed to $\mathrm{CH}_{2}$ stretching modes (according to the calculations undertaken for the peroxides, Table 2).

\section{$1800-1550 \mathrm{~cm}^{-1}$ spectral region}

For LA, containing only isolated double bonds, three main bands are observed in this interval: at $1744 \mathrm{~cm}^{-1}$, due to $\mathrm{v}(\mathrm{C}=\mathrm{O})$, and at 1659 $\mathrm{cm}^{-1}$ (the most intense feature) with a shoulder at $1640 \mathrm{~cm}^{-1}$ (Fig. S4, Supplementary Material, day 0), corresponding to the simultaneous $\mathrm{v}(\mathrm{C}=\mathrm{C})$ from the isolated cis-double bonds (Table 1).

Throughout the oxidation process, three new Raman bands arise at 1695, 1635 and $1597 \mathrm{~cm}^{-1}$ (Fig. S4). The signal at 1695 $\mathrm{cm}^{-1}$, in particular, can be assigned to the $\mathrm{v}(\mathrm{C}=\mathrm{O})$ mode of conjugated aldheydes, ${ }^{[8,15]}$ which are red-shifted due to conjugation between the $\mathrm{C}=\mathrm{O}$ and $\mathrm{C}=\mathrm{C}$ double bonds. Additionally, the Raman bands characteristic of LA in this spectral interval undergoes changes during the experiment (Fig. S4). The very weak signal at $1744 \mathrm{~cm}^{-1}$ suffers an intensity enhancement due to the contribution of carbonyl groups from chemical entities produced by oxidation. Also, an intensity enhancement in the spectral interval between 1760 and $1660 \mathrm{~cm}^{-1}$ can be observed, thanks to the contribution of distinct oxidation products containing a carbonyl group. As to the band at $1659 \mathrm{~cm}^{-1}$, ascribed to the $(C=C)$ stretching of the cis-double bonds of the fatty acid, a variation with no specific trend can be perceived when the spectra are normalised relative to the $1441 \mathrm{~cm}^{-1}$ signal (Fig. S4-Al). This can be understood in the light of the chemical changes taking place during the autooxidation process: thermally stressed samples are known to undergo conformational rearrangements (yielding trans-systems), ${ }^{[5,8,15,30]}$ and the oxidation process leads to an additional formation of trans-conjugated species (peroxides and secondary oxidation products). This diversity of unsaturated systems contributing to the Raman profile around $1700-1600 \mathrm{~cm}^{-1}$ justifies the uneven behaviour of the $1659 \mathrm{~cm}^{-1}$ band, which does not allow to relate the corresponding intensity variation to the degree of LA oxidation. In fact, when this signal is used to normalise the spectrum (Fig. S4-BI), the neighbouring Raman bands maintain the same trend as the non-normalised ones, evidencing the irrelevance of this feature for evaluating the oxidation state of the sample.

The shoulder observed at $1640 \mathrm{~cm}^{-1}$ was found to be blurred by the widening of the $1659 \mathrm{~cm}^{-1}$ feature (reflecting the presence of

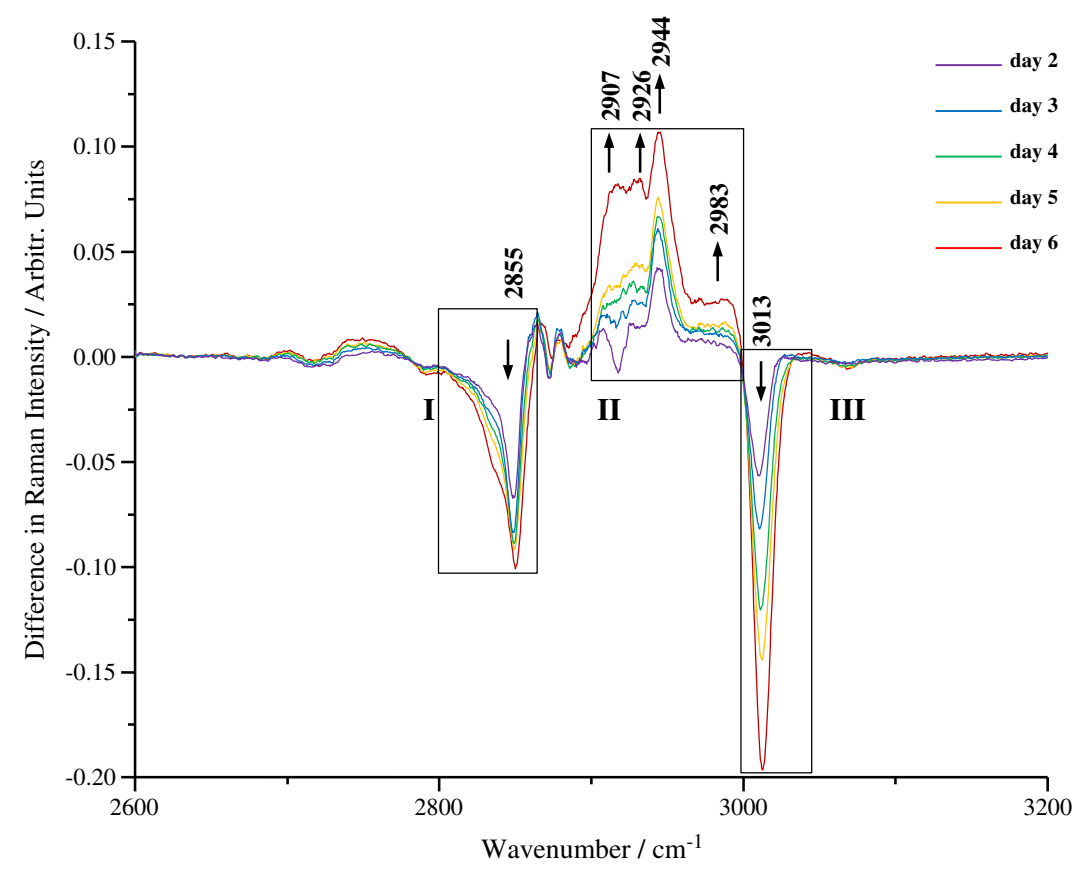

I

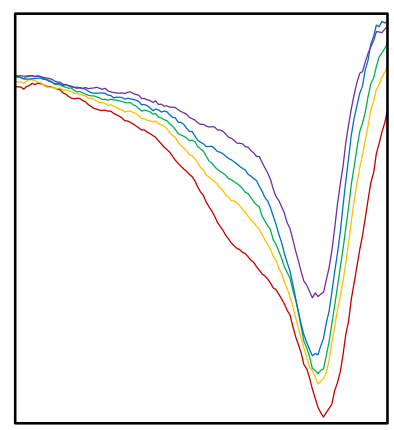

II

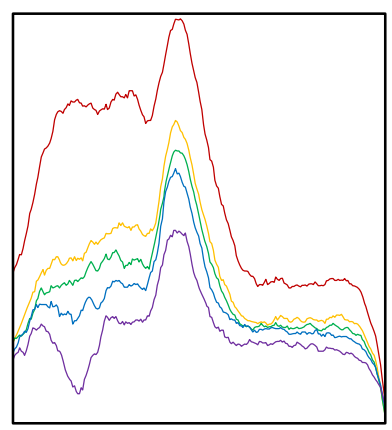

III

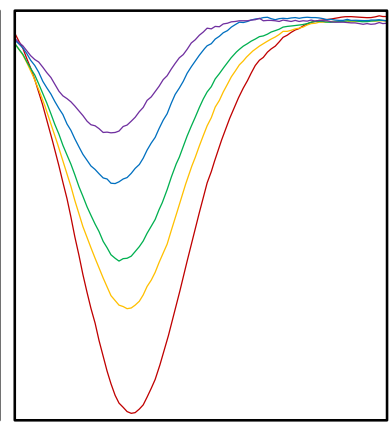

Figure 3. Difference Raman spectra $\left(2600-3200 \mathrm{~cm}^{-1}\right)$ for linoleic acid, at each day of the oxidation experiment, relative to the spectrum at day 0 . (The arrows reflect the trend of the signal intensity changes upon oxidation. I, II and III correspond to spectral expansions). This figure is available in colour online at wileyonlinelibrary.com/journal/jrs 
Table 2. Trends detected in the difference Raman spectra of linoleic acid upon oxidation - spectrum of oxidised LA at day 6 minus spectrum at day 0

\begin{tabular}{|c|c|c|c|c|c|}
\hline $\begin{array}{l}\text { Wavenumber } \\
\left(\mathrm{cm}^{-1}\right)\end{array}$ & ${ }^{\mathrm{a}}$ Trend & ${ }^{\mathrm{b}}$ Assignment & $\begin{array}{c}\text { Wavenumber } \\
\left(\mathrm{cm}^{-1}\right)\end{array}$ & Trend & Assignment \\
\hline 3013 & - & $\mathrm{U}_{\mathrm{s}}(\mathrm{CH})_{\text {cis }}$ & 1308 & + & $\delta(\mathrm{OCH})$ \\
\hline 2983 & + & $\mathrm{v}_{\mathrm{as}}(\mathrm{CH})_{\mathrm{cis}}$ & 1297 & + & $\delta(\mathrm{HC}=\mathrm{CH})_{\text {trans-conj. }}$ \\
\hline 2944 & + & $\mathrm{v}_{\mathrm{as}}\left(\mathrm{CH}_{2}\right)_{\mathrm{aliph}}$ & 1266 & - & $\delta(\mathrm{HC}=\mathrm{CH})_{\mathrm{cis}}$ \\
\hline 2926 & + & $\mathrm{v}_{\mathrm{as}}\left(\mathrm{CH}_{2}\right)_{\mathrm{aliph}}$ & 1190 & + & $\delta(\mathrm{HC}=\mathrm{CH})_{\text {conj. }}+\omega\left(\mathrm{CH}_{2}\right)_{\mathrm{aliph}}$ \\
\hline 2907 & + & $\mathrm{v}_{\mathrm{s}}\left(\mathrm{CH}_{3}\right)+\mathrm{v}_{\mathrm{as}}\left(\mathrm{CH}_{2}\right)_{\mathrm{aliph}}$ & 1165 & + & ${ }^{c} v(C-C)+v(C-C)_{c o n j .}$ \\
\hline 2855 & - & $\mathrm{U}_{\mathrm{as}}\left(\mathrm{C}^{11} \mathrm{H}_{2}\right)$ & 1118 & + & $\begin{array}{c}\delta(\mathrm{OCH})+\delta(\mathrm{HC}=\mathrm{C})+ \\
t\left(\mathrm{CH}_{2}\right)\end{array}$ \\
\hline 1737 & + & $\mathrm{v}(\mathrm{C}=\mathrm{O})_{\text {carbox. }}+{ }^{\mathrm{c}} \mathrm{v}(\mathrm{C}=\mathrm{O})$ & 973 & - & $\gamma(\mathrm{CH}=\mathrm{CH})_{\mathrm{cis}}$ \\
\hline 1695 & - & ${ }^{c} v(C=O)_{\text {conj. }}+v(C=C)_{\text {conj. }}$ & 910 & - & $\Delta\left(\mathrm{C}^{10} \mathrm{C}^{11} \mathrm{C}^{12}\right)$ \\
\hline 1672 & - & ${ }^{\mathrm{d}} \mathrm{v}(\mathrm{C}=\mathrm{C})_{\text {isolated-trans }}$ & 841 & - & $v(\mathrm{C}-\mathrm{C})_{\mathrm{I}}+r\left(\mathrm{CH}_{2}\right)_{\mathrm{I}}$ \\
\hline 1642 & + & ${ }^{\mathrm{d}} \mathrm{U}(\mathrm{C}=\mathrm{C})_{\text {conj. }}$ & 819 & + & $\gamma_{\text {ooph }}(\mathrm{CH}=\mathrm{CH})_{\text {conj. }}$ \\
\hline 1635 & + & ${ }^{c} \mathrm{v}(\mathrm{C}=\mathrm{C})_{\text {conj. }}+\mathrm{v}(\mathrm{C}=\mathrm{C})_{\mathrm{iph}}$ & 726 & - & $\gamma(\mathrm{CH}=\mathrm{CH})_{\mathrm{cis}}$ \\
\hline 1597 & + & $\mathrm{U}_{\mathrm{ooph}}(\mathrm{C}=\mathrm{C})_{\text {conj. }}$ & 251 & & skeletal mode \\
\hline 1333 & + & $\omega\left(\mathrm{CH}_{2}\right)_{\mathrm{II}}$ & & & \\
\hline $\begin{array}{l}{ }^{a} \text { Trends in intensity ch } \\
\text { work; dotted cells - pr } \\
r \text { - rocking, } \omega-\text { wagg } \\
\text { skeleton atoms; ooph } \\
\text { dAssigned according }\end{array}$ & $\begin{array}{l}\text { ye: + refe } \\
\text { int work, } \\
\text { sciss. - } \\
\text { ut-of-ph }\end{array}$ & $\begin{array}{l}\text { n increase; - refers to a decrease. } \\
\text {; light grey cells - present work, for } \\
\text { ring, } \gamma \text { - out-of-plane deformatio } \\
s \text { and } s \text { refer to antisymmetric anc }\end{array}$ & $\begin{array}{l}\text { are numbered ac } \\
\text { operoxides; dark gr } \\
\text { in-plane deforma } \\
\text { netric modes, resp }\end{array}$ & $\begin{array}{l}\text { ding to F } \\
\text { cells - lite } \\
\text { n of skele } \\
\text { tively. }{ }^{C} \text { Se }\end{array}$ & $\begin{array}{l}\text { 1(A). White cells - literature and presen } \\
\text { ure. } \delta \text {-in-plane deformation, } t \text { - twisting } \\
\text { n atoms, } \Gamma \text { - out-of-plane deformation } \\
\text { ndary oxidation products, according to }\end{array}$ \\
\hline
\end{tabular}

several oxidation species), two new bands arising at 1635 and $1597 \mathrm{~cm}^{-1}$. The former can be tentatively assigned to $v(C=C)$ of conjugated trienes (Table 2), in agreement with to Muik et al. ${ }^{[8]}$ However, its intensity increases faster than that of the neighbouring signals assigned to oxidation products (Fig. 4), thus supporting the possibility of this band being assigned to different chemical species. In turn, the feature at $1597 \mathrm{~cm}^{-1}$, not previously reported in spectroscopic studies of oxidation processes of edible oils, is presently assigned (in the light of the DFT results) to the out-of-phase $v(C=C)$ mode of the conjugated peroxides (Table 1).

Analysing the difference Raman spectra collected at different days during the experiment ( 6 days) relative to the spectrum at day 0 (free LA) allows to clearly distinguish the main features that arise from the oxidation process (Fig. 4). A new band can be found at $1672 \mathrm{~cm}^{-1}$, due to the $v(C=C)$ mode of isolated trans-double bonds, ${ }^{[7]}$ while at 1663 and $1651 \mathrm{~cm}^{-1}$, two signals with undefined trends are visible (Fig. 4-III). While the latter can be assigned to the $v(C=C)$ of the isolated cis-double bonds, the former seems to have contributions from distinct systems, which renders its assignment quite ambiguous.

$1550-650 \mathrm{~cm}^{-1}$ spectral region

Apart from the band at $1441 \mathrm{~cm}^{-1}$, which is unaffected by oxidation (Fig. S5, Supplementary Material) and therefore useful as a reference for the evaluation of the intensity changes during this process, other important signals occur in this wavenumber interval. The intensity decrease of the band at $1266 \mathrm{~cm}^{-1}$ (Fig. S5) appears as an important feature in this kind of experiment, since it is mainly due to the $\mathrm{CH}$ deformations of the two cis-double bonds (Table 1) and may thus be used as a suitable probe of the annihilation of these cis-double bonds in the fatty acid, occurring during oxidation.
Two weak bands evidencing a clear intensity enhancement throughout the oxidation process (Fig. S5) are found at 1190 and $1165 \mathrm{~cm}^{-1}$. For the oxidised samples, the former has contributions from $\delta(\mathrm{CH})$ of the conjugated moiety of the peroxides, as well as from their $\mathrm{CH}_{2}$ wagging modes, (Fig. 4-II, Table 2). In turn, the band at $1165 \mathrm{~cm}^{-1}$, clearly visible after subtracting the spectrum at day 0 from those of the oxidised species (Fig. 4-II), may be related to the presence of 2,4-decadienal, which is expected to have a strong $v(C C)$ feature at this wavenumber value. ${ }^{[8]}$ Furthermore, this signal seems to be enhanced by the contribution of a vibrational mode from the peroxides, mainly due to $v(C C)$ of the conjugated moiety (Table 2) (which is predicted to be rather intense by the DFT calculations).

Regarding the set of five bands observed between 980 and $830 \mathrm{~cm}^{-1}$, intensity variations are readily detected, the first three ones, at 973,947 and $910 \mathrm{~cm}^{-1}$, undergoing an intensity decrease (Fig. S5). The feature at $973 \mathrm{~cm}^{-1}$, assigned to the cis-olefinic moiety (Table 1), was used by other authors for evaluating the oxidation of edible oils, ${ }^{[8]}$ in good agreement with the experimental and DFT results presently shown for LA (Figure S5, Table 2). The two bands at 947 and $910 \mathrm{~cm}^{-1}$ correspond to vibrational modes exclusive of the non-oxidised $L A$, the former to $\mathrm{C}^{11} \mathrm{H}_{2}$ rocking and the latter to the $\mathrm{C}^{10} \mathrm{C}^{11} \mathrm{C}^{12}$ deformation mode (Table 1). Both undergo an intensity decrease (Fig. S5), reflecting the rearrangement from a non-conjugated $(\mathrm{C}=\mathrm{C}-\mathrm{C}-\mathrm{C}=\mathrm{C})$ to a conjugated $(\mathrm{C}=\mathrm{C}-\mathrm{C}=\mathrm{C})$ system upon oxidation. Vibrational modes specific from the peroxides are to be found within this region, namely those involving the out-of-plane $(\mathrm{CH})$ bending exclusively found in the peroxides' conjugated moiety (Table 2). These features are probably the reason for the irregular behaviour of the aforementioned band. Finally, the intensity of the signal at $841 \mathrm{~cm}^{-1}$, ascribed to the simultaneous $v(C C)$ vibrations of the whole aliphatic chain, 

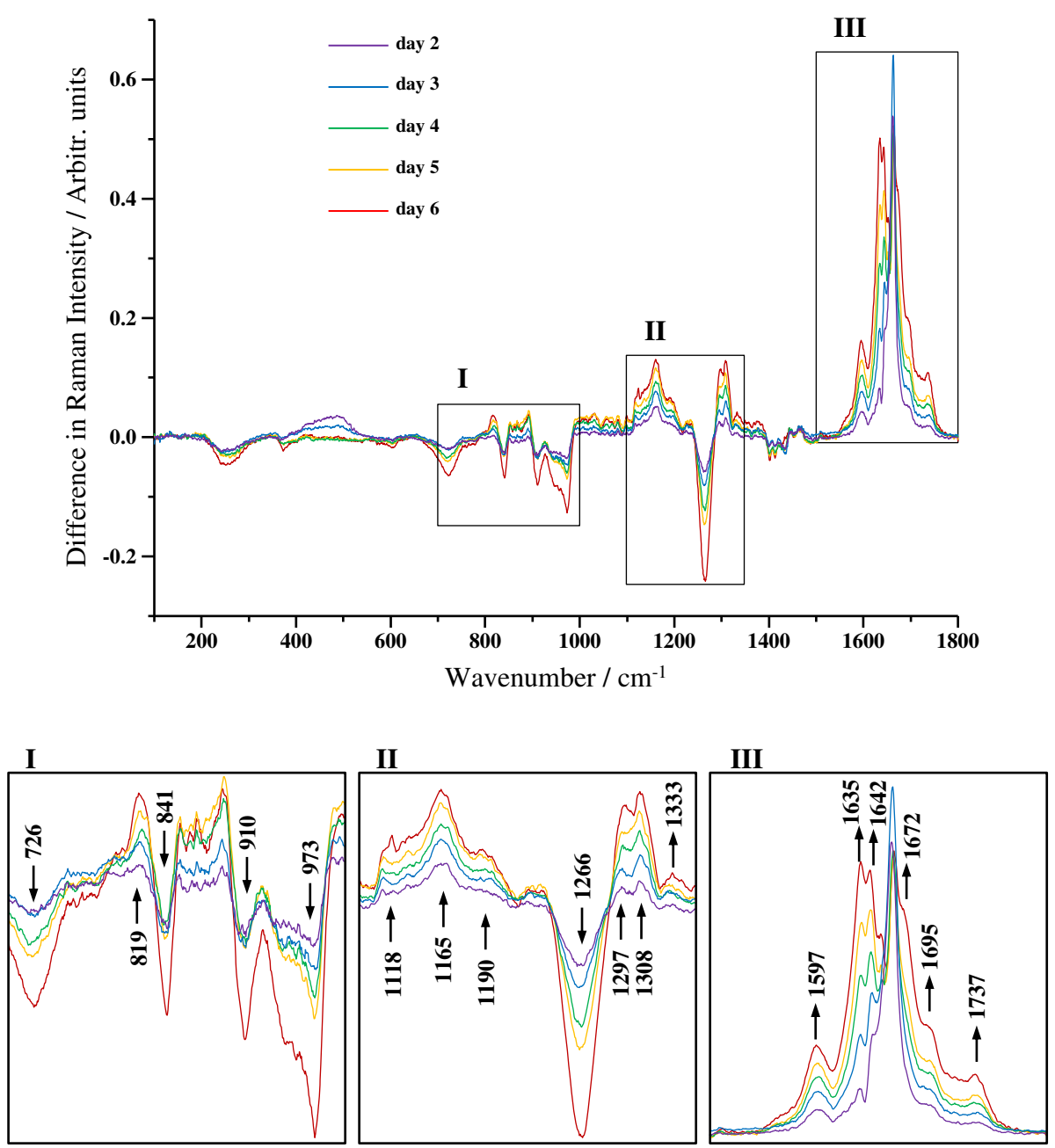

Figure 4. Difference Raman spectra $\left(100-1800 \mathrm{~cm}^{-1}\right)$ for linoleic acid, at each day of the oxidation experiment, relative to the spectrum at day 0 . (The arrows reflect the trend of the signal intensity changes upon oxidation. I, II and III correspond to spectral expansions). This figure is available in colour online at wileyonlinelibrary.com/journal/jrs

decreases markedly during oxidation. This is probably a consequence of the structural rearrangement of the aliphatic chain from the acid to the peroxides, lower intensities having been presently predicted for the vibrational modes of the latter. Additionally, the band at $726 \mathrm{~cm}^{-1}$, assigned to the $(\mathrm{CH})$ out-of-plane bending of the cis-double bonds, loses intensity (Fig. S5) during the experiment, as expected, reflecting the decrease in the ratio (LA:oxidation products).

The difference spectra in the $1000-700 \mathrm{~cm}^{-1}$ interval comprises four negative signals, at 973910,841 and $726 \mathrm{~cm}^{-1}$ (Fig. 4-I, Table 2), corresponding to an intensity loss of the bands resulting from the non-oxidised LA (Fig. S5). Meanwhile, in the $900-850 \mathrm{~cm}^{-1}$ wavenumber range, although some intensity enhancement seems to occur, the trend is not constant for the entire time period of the experiment (Fig. 4-I). This is probably due to contributions from peroxides and, eventually, to the presence of volatile secondary oxidation products (Fig. S1) that gradually degrade or evaporate, thus contributing to the complex behaviour observed in this spectral range. The difference spectra relative to day 0 (unoxidised sample) also unveil a new band at $819 \mathrm{~cm}^{-1}$ (Fig. 4-I), not detectable by simple analysis of the Raman profiles registered at the distinct time-points. In the light of the calculations, this feature is assigned to the $\mathrm{CH}$ out-of-phase bending from the conjugated structure of the peroxides, gradually formed as a function of time (Table 2).

Finally, all bands detected bellow $650 \mathrm{~cm}^{-1}$ display quite weak intensities (Fig. 2), which renders spectral subtraction unreliable in this interval, as baseline subtraction may interfere with the results. Hence, and even though some changes were observed upon oxidation (Table 1) within this spectral region, it was considered useless for evaluating the sample's oxidation degree.

\section{Conclusions}

The spectral features presently gathered for LA, along with the clear changes detected throughout the autooxidation experiment, allowed to conclude that Raman spectroscopy is a suitable and reliable technique for monitoring the oxidation degree in fatty acids. Furthermore, the use of molecular orbital calculations in combination with the spectroscopic measurements enable to achieve an accurate vibrational assignment and to ascribe specific spectral features to particular groups, both for the fatty acid and for its oxidation products, in the light of the structural changes occurring during the oxidation process. The intensity decrease of the bands at $3013 \mathrm{~cm}^{-1}$ and $1266 \mathrm{~cm}^{-1}$ - associated to the LA's cis-double bonds - can be straightforwardly related to the 
oxidation status of the sample, as well as the smooth decline of the feature at $2855 \mathrm{~cm}^{-1}$. A previously proposed approach, ${ }^{[31]}$ based on the ratio between the area of the bands located in the $1680-1620 \mathrm{~cm}^{-1}$ interval and those at ca. $1660 \mathrm{~cm}^{-1}$, was found to be unsuitable for the present analysis (involving thermal stress) due to the complexity of these features. ${ }^{[8]}$

In conclusion, the intensity decrease of the Raman bands related to the cis-double bonds of an unsaturated fatty acid emerges as an unequivocal sign of degradation through autooxidation and hence as an important tool for probing the acid's oxidation degree. Actually, the fatty acid contains only isolated cis-double bonds which constitute the oxidation sites within the molecule, being steadily and gradually suppressed throughout this process, leading to a marked weakening of the corresponding vibrational bands. In turn, the new Raman features arising upon oxidation, due to derivatives formed along the process, were found to change continuously throughout the experiment since these are often transient oxidation products.

The success of Raman spectroscopy in probing the oxidation state of a fatty acid sample, presently verified, coupled to a simpler setup and virtually no sample preparation, renders this technique a very useful and promising tool in food industry, namely for assessing the quality of edible oils in situ (e.g. rancidity, unsaturation pattern and presence of additives). Aiming at such an application, the procedure presently described should be extended to other isolated fatty acids in order to build a database of characteristic vibrational patterns, related to distinct structural features, allowing their unequivocal identification and the assessment of structural modifications within their molecule (e.g. by oxidation). Furthermore, the work presently carried out paves the way for developing a standard method for screening antioxidant capacity through Raman spectroscopy, using LA as the oxidised substrate. The antioxidant activity of the analysed samples would be measured by their ability to avoid autooxidation of this fatty acid.

\section{Acknowledgements}

The authors acknowledge financial support from the Portuguese Foundation for Science and Technology - PEst-OE/QUI/UI0070/ 2011. NFLM acknowledges PhD grant (SFRH/BD/40235/2007).

\section{Supporting information}

Supporting information may be found in the online version of this article.

\section{References}

[1] E. N. Frankel, Prog. Lipid Res. 1980, 19, 1.

[2] K. Warner, N. A. M. Eskin, Methods to Assess Quality and Stability of Oils and Fat-containing Foods, AOCS Press, Champaign, III., 1995.

[3] IUPAC, Standard Methods for the Analysis of Oils, Fats and Derivatives (7th edn), Union of Pure and Applied Chemistry, Blackwell Scientific Publications, Oxford, U.K., 1987.
[4] J. C. Allen, R. J. Hamilton, Rancidity in Foods, Elsevier Applied Science, London, New York, 1989.

[5] H. Yang, J. Irudayaraj, J. Am. Oil Chem. Soc. 2001, 78, 889.

[6] M. D. Guillen, N. Cabo, J. Agric. Food Chem. 1999, 47, 709.

[7] J. M. Chalmers, P. R. Griffiths, Handbook of Vibrational Spectroscopy, J. Wiley, New York, 2002.

[8] B. Muik, B. Lendl, A. Molina-Diaz, M. J. Ayora-Canada, Chem. Phys. Lipids 2005, 134, 173.

[9] S. Armenta, J. Moros, S. Garrigues, M. De La Guardia, Crit. Rev. Food Sci. 2010, 50, 567.

[10] F. R. Vandevoort, A. A. Ismail, J. Sedman, J. Am. Oil Chem. Soc. 1995, $72,873$.

[11] G. L. Johnson, R. M. Machado, K. G. Freidl, M. L. Achenbach, P. J. Clark S. K. Reidy, Org. Process Res. Dev. 2002, 6, 637.

[12] J. K. Agbenyega, M. Claybourn, G. Ellis, Spectrochim. Acta A 1991, 47, 1375.

[13] F. R. Vandevoort, J. Sedman, G. Emo, A. A. Ismail, J. Am. Oil Chem. Soc. 1992, 69, 1118.

[14] J. Gray, J. Am. Oil Chem. Soc. 1978, 55, 539.

[15] J. Dubois, F. van de Voort, J. Sedman, A. Ismail, H. Ramaswamy, J. Am. Oil Chem. Soc. 1996, 73, 787.

[16] V. Baeten, P. Hourant, M. T. Morales, R. Aparicio, J. Agr. Food. Chem. 1998, 46, 2638.

[17] N. A. Marigheto, E. K. Kemsley, M. Defernez, R. H. Wilson, J. Am. Oil Chem. Soc. 1998, 75, 987.

[18] H. Sadeghi-Jorabchi, R. H. Wilson, P. S. Belton, J. D. Edwardswebb, D. T. Coxon, Spectrochim. Acta A 1991, 47, 1449.

[19] B. Muik, B. Lendl, A. Molina-Diaz, M. J. Ayora-Canada, Anal. Chim. Acta 2003, 487, 211.

[20] D. Huang, B. Ou, R. L. Prior, J. Agr. Food. Chem. 2005, 53, 1841.

[21] R. Apak, K. Guclu, B. Demirata, M. Ozyurek, S. E. Celik, B. Bektasoglu, K. I. Berker, D. Ozyurt, Molecules 2007, 12, 1496.

[22] C. Sánchez-Moreno, Food Sci. Technol. Int. 2002, 8, 121.

[23] M. J. Frisch, G. W. Trucks, H. B. Schlegel, G. E. Scuseria, M. A. Robb, J. R. Cheeseman, J. J. A. Montgomery, T. Vreven, K. N. Kudin, J. C. Burant, J. M. I. Millam, S. S. lyengar, J. Tomasi, V. Barone, B. Mennucci, M. Cossi, G. Scalmani, N. Rega, G. A. Petersson, H. Nakatsuji, M. Hada, M. Ehara, K. Toyota, R. Fukuda, J. Hasegawa, M. Ishida, T. Nakajima, Y. Honda, O. Kitao, H. Nakai, M. Klene, X. Li, J. E. Knox, H. P. Hratchian, J. B. Cross, V. Bakken, C. Adamo, J. Jaramillo, R. Gomperts, R. E. Stratmann, O. Yazyev, A. J. Austin, R. Cammi, C. Pomelli, J. W. Ochterski, P. Y. Ayala, K. Morokuma, G. A. Voth, P. Salvador, J. J. Dannenberg, V. G. Zakrzewski, S. Dapprich, A. D. Daniels, M. C. Strain, O. Farkas, D. K. Malick, A. D. Rabuck, K. Raghavachari, J. B. Foresman, J. V. Ortiz, Q. Cui, A. G. Baboul, S. Clifford, J. Cioslowski, B. B. Stefanov, G. Liu, A. Liashenko, P. Piskorz, I. Komaromi, R. L. Martin, D. J. Fox, T. Keith, M. A. Al-Laham, C. Y. Peng, A. Nanayakkara, M. Challacombe, P. M. W. Gill, B. Johnson, W. Chen, M. W. Wong, J. Gonzalez, J. A. Pople, in Gaussian 03, Revision D.01, Gaussian, Inc, Wallingford CT, 2004.

[24] C. Lee, W. Yang, R. G. Parr, Phys. Rev. B Condens. Matter 1988, 37, 785; B. Miehlich, A. Savin, H. Stoll, H. Preuss, Chem. Phys. Lett. 1989, $157,200$.

[25] A. D. Becke, Phys. Rev. A 1988, 38, 3098; A. D. Becke, J. Chem. Phys. 1993, 98, 5648.

[26] G. A. Petersson, A. Bennett, T. G. Tensfeldt, M. A. Allaham, W. A. Shirley, J. Mantzaris, J. Chem. Phys. 1988, 89, 2193.

[27] C. Peng, P. Y. Ayala, H. B. Schlegel, M. J. Frisch, J. Comput. Chem. $1996,17,49$.

[28] J. P. Merrick, D. Moran, L. Radom, J. Phys. Chem. A 2007, 111, 11683.

[29] A. M. Amorim da Costa, M. P. M. Marques, L. A. E. Batista de Carvalho, J. Raman Spectrosc. 2003, 34, 357;

A. M. Amorim da Costa, M. P. M. Marques, L. A. E. Batista de Carvalho, Vib. Spec. 2004, 35, 165.

[30] A. A. Christy, Open Spec. J. 2010, 4, 41.

[31] H. Sadeghi-Jorabchi, P. J. Hendra, R. H. Wilson, P. S. Belton, J. Am. Oil Chem. Soc. 1990, 67, 483 